\title{
The nature of nature as a stakeholder
}

\author{
Matias Laine \\ University of Tampere
}

School of Management,

FI-33014 University of Tampere, Finland.

Email: firstname.lastname[at]uta.fi.

“Accepted author manuscript” version (postprint)

\section{Original publication:}

Laine, M. (2010), The nature of nature as a stakeholder. Journal of Business Ethics, 96(suppl. 1), 73-78.

doi.org/10.1007/s 10551-011-0936-4

\section{Acknowledgments:}

This paper stems from the author's discussions with the late Professor Juha Näsi, whose input on an early version of this paper is gratefully acknowledged. The usual caveat still applies.

\begin{abstract}
There is a longstanding debate in the stakeholder literature as to who and what really counts as the stakeholders of the firm. Likewise, there have been discussions on whether nature should be considered a stakeholder of the firm. However, one seldom encounters any definitions of the key concepts, that is of 'nature or 'the natural environment'. We seek to contribute to the debate by taking a closer look at what this thing called nature actually is. In addition, we discuss the implications of this conceptual refinement for the stakeholder model. In order to reinforce the status of the natural environment in the stakeholder model, we propose that any visualisation of a stakeholder network should be embedded in the natural environment.
\end{abstract}

Keywords: Natural environment, Nature, Stakeholder 


\section{The nature of nature as a stakeholder}

\section{Introduction}

Stakeholder thinking has been a salient part of the academic management literature for decades (Freeman 1984, see also Rhenman and Stymne, 1965; Ahlstedt and Jahnukainen, 1971; Näsi, 1979). Over the years the relationship between business and the natural environment has attracted ever increasing attention from both academia and the society at large. Likewise, in the discussions concerning stakeholder theories some authors have explicitly proposed that the natural environment should be considered a stakeholder of the firm (e.g. Starik, 1995; Stead and Stead, 1996). However, in many cases the natural environment has simply been positioned either as a stakeholder or not without any articulated arguments.

The aim of this paper is to take a closer look at what those things called 'nature' and 'the natural environment really are. We first go briefly through some definitions of stakeholders proposed in the literature. Next, we proceed to the prior discussion regarding the status of the natural environment in the stakeholder model together with the arguments presented in support of different conceptualisations. Thereafter we focus on the definitions of 'nature' and 'the natural environment'. In the final section we discuss the possible implications of these definitions for the stakeholder model and draw some conclusions.

\section{Who and what counts as a stakeholder}

There is a longstanding debate in the stakeholder literature as to who and what really counts as the stakeholders of the firm. Thus, before progressing to discussing the position of the natural environment in the stakeholder model, we take a brief look at the various definitions of stakeholders proposed so far in the literature. In general, a rough distinction can be made between the broad and the narrow views of the stakeholders (see Freeman and Reed, 1983; also Fassin, 2009; Mitchell, Agle and Wood, 1997). Freeman's (1984, p. 46) classic definition is one of the broadest: "A stakeholder in an organization is (by definition) any group or individual who can affect or is affected by the achievement of the organization's objectives". According to Mitchell, Agle and Wood (1997), the broad 
view of stakeholders stems from the idea that organizations can indeed affect or be affected by virtually anyone. Such a broad view has been criticised for being of only limited practical value, due to both its enormous complexity and virtual all-inclusiveness. Accordingly, some scholars have attempted to define stakeholders in a more concrete and limited way. These definitions are likewise varied. Hill and Jones (1992, p. 133), for instance, base their definition on claims: "the term stakeholder refers to groups of constituents who have a legitimate claim on the firm”. Phillips (1997; also Phillips and Reichart, 2000), in turn, approaches stakeholder identification by using the principal of fairness. In a recent contribution, Fassin (2009, p. 116) refers to stakeholders as "any individual or group that maintain a stake in an organisation in the way that a shareholder possesses shares". Moreover, Fassin (p. 121) elaborates on the stakeholder model and proposes a distinction between stakeholders, stakewatchers and stakekeepers. For him, the stakeholders are "essentially the classic stakeholders in the original narrow model". The stakekeepers, like pressure groups, "do not really have a stake themselves, but they protect the interests of real stakeholders". Finally, the stakewatchers, like the regulators, "have no stake in the firm but have influence and control".

In short, there is a plethora of definitions for stakeholders (see Mitchell et al., 1997). As Phillips and colleagues (2003, p. 479) put it: "the term means different things to different people". Likewise, the status of the natural environment also varies in the different conceptualisations. In this paper we contend that the natural environment should be given a more prominent and visible position in the stakeholder model. Therefore, we now proceed to discuss how the natural environment has been positioned in earlier contributions.

\section{Perspectives including the natural environment as a stakeholder of the firm}

One of the earliest accounts considering the natural environment as a stakeholder of the firm was presented by Näsi (1980, 1982). Näsi's conceptualization is reproduced in Figure 1. In his contribution stakeholders are described as follows: "Interest groups and interest systems consist of individuals, groups, institutions, and of the natural environment which interact with the firm. All these systems have different expectations and demands on the firm and the firm is also responsible for all these systems" (Näsi, 1980, 1982). However, in hindsight it may be noted that nature has been positioned as a 
stakeholder without any explicit argumentation as to why this is the case. Further, even though Näsi uses the term 'natural environment' in the body of his text, in his figures (reproduced here as Figure 1) the term 'nature` is used.

\section{INSERT FIGURE 1 ABOUT HERE}

Starik has actively argued in favour of giving the natural environment a prominent position in the stakeholder model. In an earlier paper Starik (1995) goes through arguments for and against stakeholder status and ends up maintaining that the natural environment should indeed be considered a stakeholder. However, he admits that adding the natural environment to the stakeholder map could be "a daunting endeavour" (Starik, 1995, p. 215). More recently, in a co-authored paper Driscoll and Starik (2004) maintain that the natural environment should be considered to be the primordial stakeholder. Drawing on the seminal contribution by Mitchell, Agle and Wood (1997), Driscoll and Starik add proximity to the stakeholder attributes of power, legitimacy and urgency by Mitchell and colleagues. They further discuss the four attributes and conclude that the natural environment should be considered the primary and primordial stakeholder of the firm (see also Haigh and Griffiths, 2009). According to Driscoll and Starik (2004), the natural environment exists in a relation of reciprocal dependence with the business organisations. They maintain that the natural environment holds coercive power and has attained legitimacy from the world's scientific community. Moreover, Driscoll and Starik (2004, p. 61) argue that even though the model proposed by Mitchell, Agle and Wood does not focus "on the subtle, the silent and the slowly evolving", the natural environment's claims are urgent through its holding of coercive power. In fact, Driscoll and Starik (2004) argue that the limited conceptions of power dominating the stakeholder thinking serve as a powerful blinder to the importance of many legitimate stakeholders, including the natural environment.

Similarly Stead and Stead (1996) also consider the natural environment as a stakeholder of the firm. In their view the natural environment should be seen as the ultimate stakeholder, since it differs fundamentally from the other stakeholder groups. For Stead and Stead the key concept is Earth, which is simultaneously the source of and the sink for all human economic activity. The argument rests on two main reasons: first, the immense scope of the earth encompassing all human activities and, second, on the human proxies 
advancing earth's position as an important entity for the firm. In a later paper (Stead and Stead, 2000) they also note how taking care of the earth is a legitimate ethical stance for companies.

Wheeler and Sillanpää (1997) present yet another perspective on the position of the natural environment. Their description includes a fourfold typology dividing stakeholders on the basis of social/non-social and primary/secondary classifications. In this typology the natural environment is given a primary non-social position. This entails that the natural environment has rights, which may be affected by the firm. However, as a nonsocial stakeholder the natural environment cannot directly communicate with the firm, but has to have human proxies to speak on its behalf (see Fassin, 2009).

\section{Arguments why the natural environment should not be included as a stakeholder}

There are some main arguments based on which other commentators have maintained that the natural environment should not be accorded any status as a stakeholder. Firstly, one of the most essential of these is the question regarding the theoretical rigour and clarity of the whole stakeholder model. It has been argued (e.g. Phillips and Reichart, 2000; Orts and Strudler, 2002; Fineman and Clarke, 1996) that if the natural environment is given stakeholder status, the whole concept of stakeholder becomes diluted. Phillips and Reichart (2000, p. 189; also Phillips, 1997) even state that if the natural environment is considered a stakeholder through its presence within the business environment of a firm, then everything existing in the firm's business environment also merits similar status.

Secondly, commentators have questioned whether the human's moral obligations towards the natural environment are valid reasons for giving the natural environment stakeholder status. Phillips and Reichart (2000) maintain that the natural environment may merit moral considerations of its own, but see this as an issue apart from its possible status as a stakeholder. In their view the natural environment merits stakeholder considerations only instrumentally.

Thirdly, it has been argued that stakeholder status should be limited to humans. Orts and Strudler (2002), for instance, argue that the natural environment cannot be a stakeholder 
since it has neither a mind nor any needs as humans understand them. Similarly, Näsi et al. (1998) describe this line of argument by noting that "nature cannot speak". Moreover, Phillips and Reichart (2000) point out that there are human proxies advocating for the natural environment.

All in all, the discussion regarding the position of the natural environment in the stakeholder model has continued for quite some time. However, we maintain that one seldom comes across any articulated definitions of the phenomenon discussed in these papers. In addition, the concepts are often used more or less interchangeably. Starik (1995) uses the concepts 'natural environment', 'non-human nature', and at times also 'nature' virtually indiscriminately. In their critique of Starik's paper Phillips and Reichart (2000) refer to even more concepts, namely 'the natural environment', 'non-human natural environment', 'non-human nature', 'nature', 'the natural world', and 'the nonhuman natural entities`. Likewise, Orts and Strudler (2002) employ the terms 'nature' and 'natural environment' interchangeably, albeit without mentioning this explicitly in their paper. Thus, the papers appear to assume there is some kind of a common understanding of the 'nature' and of 'the natural environment' the scientific community and society at large subscribe to, making it superfluous to define these concepts. A somewhat clearer position is taken in Driscoll and Starik (2004) and Stead and Stead (2000), to which we return later. As a whole, however, we concede that the concepts are rather complex and that taking a look at them in more detail is essential for further discussions on the position of the natural environment in the stakeholder model. Thus, it is this field to which the paper next progresses.

\section{What is this thing called nature?}

"All at once nature is innocent, is unprovided, is sure, is unsure, is fruitful, is destructive, is pure force and is tainted and cursed." (Williams, 1980 p. 72.)

Historically, humankind's relationship with nature has varied. Macnaghten and Urry (1998) describe how nature was long considered to be a goddess, a divine mother or an absolute monarch. The developments of new sciences such as physics, astronomy and mathematics from around the sixteenth and seventeenth centuries onwards had major effects on how nature was understood. Nature became to be seen through how it was 
materially constituted. (Macnaghten and Urry, 1998.) Related to these developments, Williams describes how nature came to be conceptualised in a new way: "Nature, in this new sense, was in another and different way all that was not man: all that was not touched by man, spoilt by man: nature as the lonely places, the wilderness" (Williams, 1980, p. 77). Nature was "out there", and thus became something else, "the other", which is positioned in opposition and distinction to human society (see Haila, 2000).

However, what is it we talk about when we in modern societies talk about nature? Defining nature appears to be rather complex (see Lähde, 2008). Still, one can assume that most humans have some kind of an understanding of nature. It is doubtful, however, whether it is possible to find a universally applicable definition for it. For instance, Macnaghten and Urry (1998) argue that no singular nature exists, only natures. They further maintain that all conceptualisations of nature are historically, geographically and socially constructed (Macnaghten and Urry, 1998, p. 15, see also Williams, 1980).

It is beyond the scope of our paper to discuss these developments in much more detail (but see Haila and Dyke, 2006; Macnaghten and Urry, 1998; Williams, 1980; Thomas, 1983). However, we wish to draw attention to one conceptual difference, which to the best of our knowledge has not been paid much attention in the stakeholder literature so far. We maintain there is an important distinction between the concepts of 'nature' and 'the natural environment'. The natural environment surrounds (Ingold, 2000; see also Haila and Lähde, 2003). This implies that there is something in the middle, which is then surrounded by the natural environment. Nature, in turn, is not situated around anything, but is present everywhere. Williams (1980, p. 75) has argued that the most decisive question regarding the definition of nature is whether humans are included in it. The answer seems fairly obvious: humans are creatures of nature (Haila, 2000). Even though this appears self-evident, the matter has apparently not been paid much attention in previous presentations regarding the natural environment's possible position as a stakeholder. Exceptions to this are Driscoll and Starik (2004), who mention this matter, and Stead and Stead (2000), who briefly discuss the difference between positioning humans with nature and humans over nature. Still, Driscoll and Starik (2004), for instance do talk about 'human nature', 'non-human nature', 'the natural environment' and 'nature', without exactly distinguishing between the concepts. 
As a whole, many previous papers in this area make an implicit distinction between human society and nature. In this perspective humans are not in nature, but above it (see Haila, 2000). Presenting such a dichotomy in the stakeholder model may in fact further widen the socially constructed gap between humankind and nature, causing further problems in terms of our ability to live with and within nature (in the management literature, see e.g. Gladwin et al., 1995; Purser et al., 1995; Shrivastava, 1994, 1995). Instead, the dichotomy further (re)constructs and reinforces the image of humans trying to manage nature. We next move on to the stakeholder framework and further discuss the possible implications of this conceptual refining on it.

\section{Nature and the natural environment in the stakeholder model}

To recap, some commentators have proposed that nature should be given status of a stakeholder of the firm. However, once we understand human beings as being part of nature, the situation becomes rather complex. If the human is a natural creature, is not everything humans do also natural? Thus, it seems all the actors in the stakeholder model are parts of nature, implying that nature is omnipresent in the stakeholder model. Driscoll and Starik (2004) argue that this is a reason to include nature among the stakeholders of the firm. However, we are not that convinced of this line of reasoning. If something is an intrinsic part of the whole, how does this make the whole a stakeholder of the part? We would rather argue that in this case anything taking place around the part is merely a small detail inside the whole, whereas considering the whole as a stakeholder of the part would construct the whole as something distinct of the part, further implying that those parts are no longer within the whole, i.e. nature, but outside of it.

In addition, at the same time nature was to be everywhere, it would actually be nowhere in the model, since being pervasively present in all places is tantamount to being taken for granted, and hence invisible, perhaps unimportant. Further, what would be the point of thinking how 'nature' is represented in a stakeholder model if humans and human action were part of nature? Therefore, it appears to us that talking about 'nature' as a stakeholder takes us nowhere.

The case is rather different once we look at the concept of 'natural environment'. As we noted earlier, the natural environment is something which surrounds something else. 
Therefore, it ought to be considered as something surrounding the firm. Furthermore, one could claim that the natural environment is by definition around all the stakeholders of the firm. This conceptualisation would lead to positioning a particular stakeholder network in a timely and spatially limited natural environment as in Figure 2.

\section{INSERT FIGURE 2 ABOUT HERE}

\section{So what? Discussing the implications}

Stakeholder thinking has been successful in providing tools for managers to understand the broader social context in which their organisations operate. Fassin (2008) argues that this success is due to the power of the model's visual simplicity. The visual presentations portray a network of relations within which the organisation is positioned. However, the stakeholder networks and practical conceptualisations tend to portray organisations as operating within a social and economic network only. We maintain that all human activities are ultimately dependent on the natural environment (Driscoll and Starik, 2004; Stead and Stead, 1996) and suggest therefore that the natural environment should be taken into account by all human organisations. Driscoll and Starik (2004, p. 65) argue that "organizations must interact with the natural environment for their physical survival, making nature a ubiquitous stakeholder of all human organizations". However, in line with Phillips and Reichart (2000) and Orts and Strudler (2002) we maintain that the natural environment should not be considered as a stakeholder as are human groups and individuals. In our view such an inclusion does not highlight the special nature of the natural environment.

Fassin (2009) maintains that the stakeholder identification is only a first step in the process of evaluating how the organisation subsequently interacts with its stakeholder network. Elsewhere, Fassin (2008) has argued that graphical representations of stakeholder frameworks are sensemaking constructions, which inevitably simplify reality. We acknowledge the power of these models. Hence, in order to reinforce the status of the natural environment in the stakeholder model, we propose that any visualisation of a stakeholder network should be embedded in the natural environment as in Figure 2. By embedding the stakeholder networks in the natural environment our contribution gives the natural environment enhanced visibility as the surrounding context in which all 
economic activity takes place. In our view such increased visibility could lead to the natural environment also gaining more prominence in managerial considerations concerning the organisations' activities and interactions with the natural environment. Moreover, this conceptualisation is not dependent on the way stakeholders are defined, as any representation of a stakeholder network can be embedded in the natural environment.

However, it is uncertain how well this conceptualisation of the position of the natural environment actually improves the state of the environment in the long run. Once the natural environment is taken as the background of the stakeholder network, it becomes in a sense relegated to the periphery. Thus, in this way the natural environment would once again become the other. Some commentators have noted that such a dichotomy of culture-nature is harmful and should be abandoned (e.g. Haila, 2000). Nevertheless, we concur with Driscoll and Starik (2004, p. 69) and argue that "the inherent interdependency between the global economy and the global ecology" needs to be recognised. Therefore, we maintain that it is important to make the natural environment somehow visible in the stakeholder model, since if it is not there at all, it would not even be the other, but simply non-existent. Our take is embedding the stakeholder network in the natural environment. We acknowledge that this brief paper has not treated the subject exhaustively and hope that others will further develop the conversation. 


\section{References:}

Ahlstedt, L. and Jahnukainen, I. (1971), Yritysorganisaatio yhteistoiminnan ohjausjärjestelmänä [in Finnish: The organization of a firm as a management system for co-operation], Weilin and Göös, Helsinki.

Driscoll, C. and Starik, M. (2004), The primordial stakeholder: Advancing the conceptual consideration of stakeholder status for the natural environment, Journal of Business Ethics, Vol. 49, pp. 55-73.

Fassin, Y (2008), Imperfections and shortcomings of the stakeholder model's graphical representation, Journal of Business Ethics, Vol. 80: pp. 879-888.

Fassin, Y. (2009), The stakeholder model refined, Journal of Business Ethics, Vol. 84, pp. 113-135.

Fineman, S. and Clarke, K. (1996), Green stakeholders: Industry interpretations and response, Journal of Management Studies, Vol. 33 No. 6, pp. 715-730.

Freeman, R. E. (1984), Strategic management: A stakeholder approach, Pitman Publishing, Boston.

Freeman, R.E. and Reed, .D.L. (1983), Stockholders and stakeholders: A new perspective on corporate governance. California Management Review, Vol. 25 No 3, pp. 88-106.

Gladwin, T.N., Kennelly, J.K. and Krause, T.S. (1995), Shifting paradigms for sustainable development: Implications for management theory and practice. Academy of Management Review, Vol. 20 No 4, pp. 874-907.

Haigh, N. and Griffiths, A. (2009), The natural environment as a primary stakeholder: The case of climate change. Business Strategy and the Environment, Vol. 18 No 6, pp. 347-359. 
Haila, Y. and Dyke, C. (eds.) (2006), How nature speaks? The dynamics of the human ecological condition. Duke University Press, Durham.

Haila, Y. and Lähde, V. (2003), Luonnon poliittisuus: mikä on uutta? [in Finnish: The political nature of nature: what is new?], in Haila, Y. and Lähde, V. (eds.), Luonnon politiikka [in Finnish: Politics of nature], Vastapaino, Tampere.

Haila, Y. (2000), Beyond the nature-culture dualism, Biology and Philosophy, Vol. 15, pp. 155-175.

Hill, C.W.L. and Jones, T.M. (1992), Stakeholder-agency theory. Journal of Management Studies, Vol. 29, pp. 131-154.

Ingold, T. (2000), The perception of environment: Essays in livelihood, dwelling and skill, Routledge, London.

Jones, T.M. (1995), Instrumental stakeholder theory: A synthesis of ethics and economics, Academy of Management Review, Vol. 20 No 2, pp. 404-437.

Jones, T.M. and Wicks, A.C. (1999), Convergent stakeholder theory, Academy of Management Review, Vol. 24 No 2, pp. 206-221.

Lähde, V. (2008), Rousseau's rhetoric of 'nature`. Acta Universitatis Tamperensis 1344. Academic Dissertation, University of Tampere.

Macnaghten, P. and Urry, J. (1998), Contested Natures, Sage, London.

Mitchell, R.K., Agle, B.R. and Wood, D.J. (1997), Toward a theory of stakeholder identification and salience: defining the principle of who and what really counts, Academy of Management Review, Vol. 22 No. 4, pp. 853-886.

Näsi, J. (1979), Yrityksen suunnittelun perusteet [in Finnish: The basis of corporate planning], University of Tampere, School of Business Administration, Series A1: 15, Tampere. 
Näsi, J. (1980), Towards a deeper comprehension of the social responsibility firms: Some philosophical, conceptual and methodological frameworks for scientific research. A paper presented at the Turku Conference on Social Responsibility in Marketing, May 1980.

Näsi, J. (1982), Towards a deeper comprehension of the social responsibility firms: Some philosophical, conceptual and methodological frameworks for scientific research, In Social Responsibility in Marketing, Publication of the Turku School of Economics, Series A-2, Turku.

Näsi, J., Näsi, S. and Savage, G.T. (1998), Nature as a stakeholder: One more speculation, in Calton, J. and Rehbein, K. (eds), Proceedings of the Ninth Annual Meeting of the International Association for Business and Society, pp. 509-512.

Orts, E.W. and Strudler, A. (2002), The ethical and environmental limits of stakeholder theory, Business Ethics Quarterly, Vol. 12 No. 2, pp. 215-233.

Phillips, R.A. (1997), Stakeholder theory and a principle of fairness, Business Ethics Quarterly, Vol. 7 No 1, pp. 51-66.

Phillips, R.A., Freeman, R.E. and Wicks, A.C. (2003), What stakeholder theory is not, Business Ethics Quarterly, Vol. 13 No 4, pp. 479-502.

Phillips, R.A. and Reichart, J. (2000), The environment as a stakeholder? A fairnessbased approach, Journal of Business Ethics, Vol. 23, pp. 185-197.

Purser, R.E., Park, C. And Montuori, A. (1995), Limits to anthropocentrism: Towards an ecocentric organization paradigm. Academy of Management Review, Vol. 20 No 4, pp. 1053-1089.

Rhenman, E. and Stymne, B. (1965), Företagsledning I en föränderlig värld [in Swedish: Corporate management in a changing world], Aldus/Bonniers, Stockholm. 
Shrivastava, P. (1995), Ecocentric management for a risk society. Academy of Management Review, Vol. 20 No 1, pp. 118-137.

Shrivastava, P. (1994), CASTRATED environment: GREENING organization studies. Organization Studies, Vol. 15 No 5, pp. 705-726.

Starik, M. (1995), Should trees have managerial standing? Toward stakeholder status for non-human nature, Journal of Business Ethics, Vol. 14, pp. 207-217.

Stead, J.G. and Stead, E. (2000), Eco-enterprise strategy: Standing for sustainability, Journal of Business Ethics, Vol. 24, pp. 313-329.

Stead, W.E. and Stead, J.G. (1996), Management for a Small Planet. $2^{\text {nd }}$ edition. Sage, Thousand Oaks.

Thomas, K. (1983), Man and the natural world. Changing attitudes in England 15001800. Allen Lane, London.

Wheeler, D. and Sillanpää, M. (1997), The stakeholder corporation, Pitman Publishing, London.

Williams, R. (1980), Ideas of Nature, in Williams, R. (ed.), Problems in Materialism and Culture, Verso, London. 


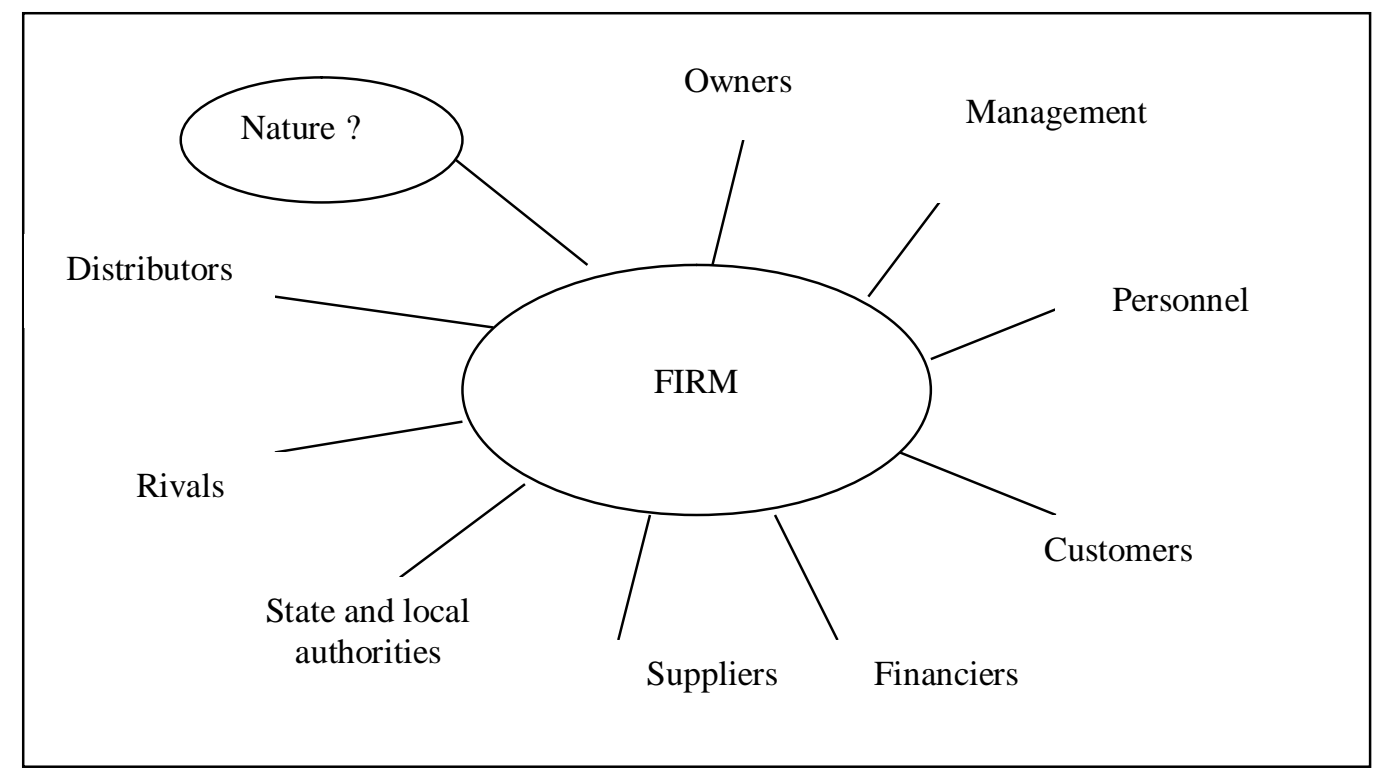

Figure 1: Can nature be a stakeholder? Adapted from Näsi $(1980,1982)$.

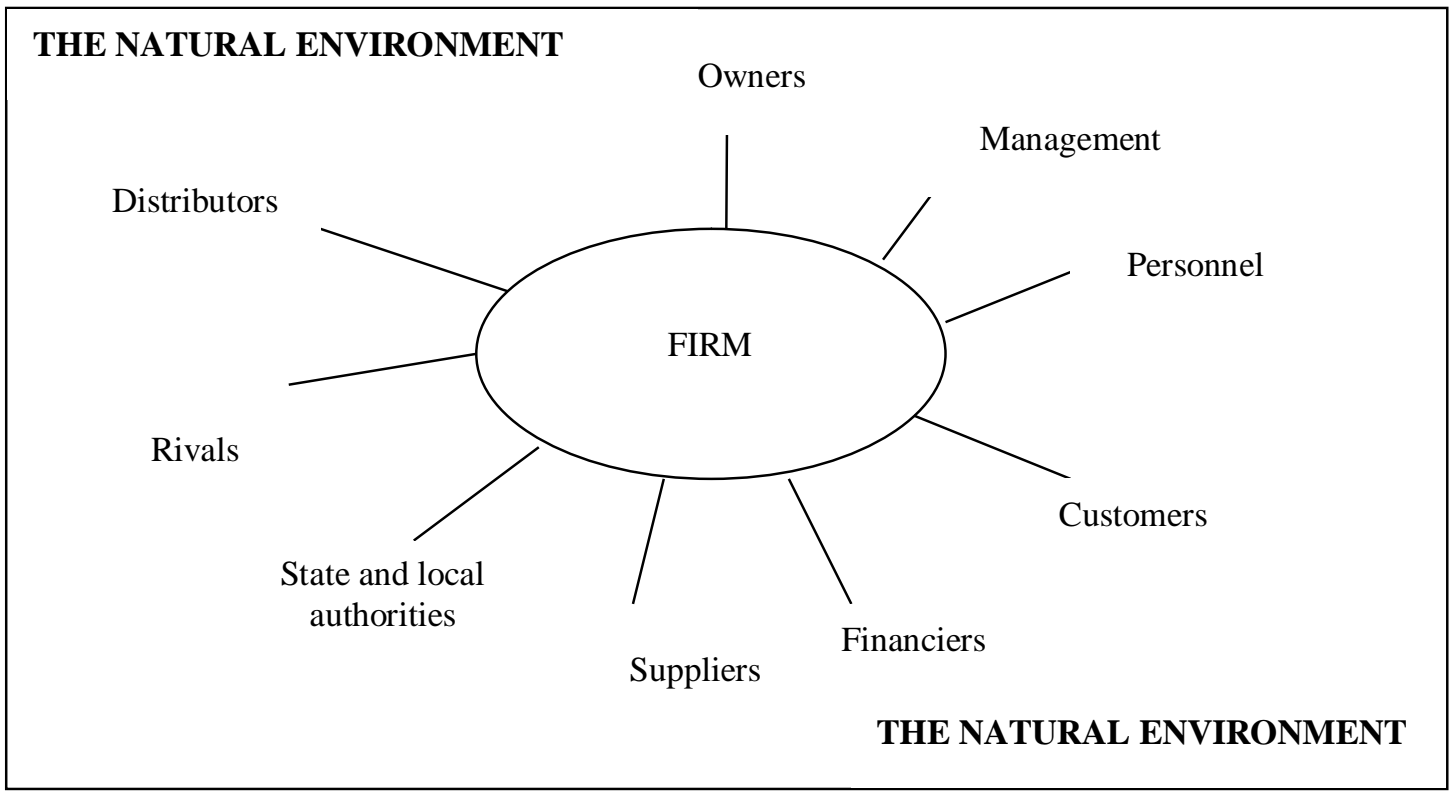

Figure 2: The stakeholder network is surrounded by the natural environment. 